\title{
Box-Behnken Experimental Design for the process optimization of Strontium substituted Hydroxyapatite synthesis
}

\author{
Kavitha.M \\ PSG College of Technology \\ Coimbatore, India
}

\author{
R.Subramanian \\ PSG College of Technology \\ Coimbatore, India
}

\author{
S.Manojkumar \\ PSG College of Technology \\ Coimbatore, India
}

\begin{abstract}
Hydroxyapatite is the major mineral constituent of vertebrate bones and teeth can significantly increase the biocompatibility and bioactivity of man-made biomaterials. Strontium substituted Hydroxyapatite, a bioceramic was successfully synthesized by solution combustion method using calcium acetate and diammonium hydrogen orthophosphate as precursors. Statistical Design of experiments was employed as a tool for systematic evaluation and investigation of the influencial process variables. Limited research was found on combustion synthesis of Sr substituted hydroxyapatite. The main objective of this work is to understand the effects of three important process parameters, synthesis time, ignition temperature and \% Sr substitution on the resulting yield and crystallite size. Contour plots were generated to study the interaction between these factors. A specific approach based on Box-Behnken design was used to evaluate these parameters and to optimize them for a more effective synthesis. Mathematical models were developed for each of the measured responses yield and crystallite size. The adequacy of the developed model was checked using analysis of variance technique and experimental validation. It has been observed that all the three parameters significantly affect the response variables. The maximum yield can be obtained when the synthesis is done at $500^{\circ} \mathrm{C}$ for 30 minutes and the crystallite sizes increases with the \% Sr substitution.
\end{abstract}

Keywords: Hydroxyapatite, Strontium, Design of Experiments, Box-Behnken, optimization, yield, crystallite size

\section{INTRODUCTION}

Calcium phosphate ceramics such as hydroxyapatite $\left[\mathrm{Ca}_{10}\right.$ $\left.\left(\mathrm{PO}_{4}\right)_{6}(\mathrm{OH})_{2}\right]$ is one of the most effective biocompatible material and is found to be the major component of the bone. This material is the most promising implant coating materials for orthopedic and dental applications due to their good biocompatibility. The superior biocompatibility of calcium phosphates contributed by their compositional resemblance with the bone mineral has allowed them to be used [1]. The greatest potential for bone substitution is shown by materials based on hydroxyapatite (HAp), which can develop tight bonding with bone tissue, exhibits excellent biocompatibility, osteoconductive behavior, is stable toward bioresorption, and has no adverse effects on the human organism [2]. Synthetic HAp nanoparticle is similar in crystal lattice to natural bone and can be used as bone substitute or dental enamel remineralization material. However, synthetic pure HAp nanoparticle has some shortcomings, such as the weak antibacterial property, the high degree of crystallinity and the stability of the structure, which lead to low biodegradation and poor effect for implant use or dental care use [3]. Therefore, it is necessary to improve its properties to use it as biomaterial. Incorporation of metal ions into the HAp structure can improve the properties of HAp, metal ions such as $\mathrm{Ag}^{+}, \mathrm{Cu}^{2+}$ in the structure can affect its solubility, crystallinity, morphology and lattice parameters, and even improve its antibacterial property. Strontium (Sr) is one of the essential trace elements in human body, which can enhance the strength of bone and prevent caries. $\mathrm{Sr}$ and $\mathrm{Ca}$ share the same group in the periodic table of elements, $\mathrm{Sr}$ may replace $\mathrm{Ca}$ to form Strontium substituted hydroxyapatite, resulting in the improvement of solubility and Biodegradability [4-8]. Strontium can replace calcium in hydroxyapatite, and hence in bone, without much difficulty. It is reported that the stable strontium is non-toxic even when it is administered in large doses in our body for prolonged periods.

Many researchers reported on the preparation methods of Strontium substituted Hydroxyapatite (Sr-HAp) nanoparticles are sol-gel, precipitation and hydrothermal, by which the nanoparticles usually need to be calcined to improve the crystal structure at a high temperature of about $900^{\circ} \mathrm{C}$, which may cause the nanoparticles to decompose. However solution combustion synthesis is a suitable method to produce Sr-HAp powder at a low ignition temperature. The aim of this work is to examine the influence of process parameters on synthesized Sr-HAp properties and determine an optimum set of process variables to produce Sr-HAp powders of desired characteristics. Design of Experiments (DoE) is employed to investigate the influencial process variables of combustion synthesis and to optimize them. From the literatures, the following observations have been made: (i) The initial furnace/ignition temperature was found to be a very important reaction parameter. The lower value of furnace temperature was selected as $400^{\circ} \mathrm{C}$ and the upper value as $600^{\circ} \mathrm{C}$. (ii) time for the reaction was also considered as another major factor for the complete transformation to HAp (iii) the lower and upper limits of substitutions selected in this experiment are 0 and $30 \%$ Sr into hydroxyapatite.

\section{MATERIALS AND METHODS}

Response surface methodology is a collection of statistical and mathematical method that are useful for the modeling and analyzing engineering problems. In this technique, the main objective is to optimize the response surface that is influenced by various process parameters. Response surface methodology also quantifies the relationship between the controllable input parameters and the obtained response surfaces [9-10]. The design procedure of response surface methodology is as follows: (i) Designing of a series of experiments for adequate and reliable measurement of the response of interest, (ii) Developing a mathematical model of the second order response surface with the best fittings, (iii) Finding the optimal set of experimental parameters that produce a maximum or minimum value of response, (iv) Representing the direct and interactive effects of process 
parameters through two and three dimensional plots. The factors are investigated at three levels +1 (high), 0 (middle) and -1 (low). The percentage $\mathrm{Sr}$ substitution, ignition temperature and synthesis time are taken as the important influential process variables and tabulated in Table 1 . These are evaluated against yield and crystallite size of the produced Sr-HAp. If all variables are assumed to be measurable, the response surface can be expressed as follows,

$\mathrm{Y}=\mathrm{f}\left(\mathrm{x}_{1}, \mathrm{x}_{2}, \mathrm{x}_{3}, \ldots \ldots \mathrm{x}_{\mathrm{k}}\right)$

where $y$ is the answer of the system, and xi the variables of action called factors. The goal is to optimize the response variable $\mathrm{y}$. It is assumed that the independent variables are continuous and controllable by experiments with negligible errors. It is required to find a suitable approximation for the true functional relationship between independent variables and the response surface. Usually a second-order model is utilized in response surface methodology.

$\mathrm{Y}=\mathrm{b}_{0}+\sum \mathrm{b}_{\mathrm{i}} \mathrm{X}_{\mathrm{i}}+\mathrm{b}_{\mathrm{ij}} \mathrm{X}_{\mathrm{i}} \mathrm{X}_{\mathrm{j}}+\mathrm{b}_{\mathrm{ii}} \mathrm{X}_{\mathrm{ii}}^{2}+\varepsilon_{g} \quad$ (Eq.2)

Where $i, j$ vary from 1 to number of process variables, coefficient $b_{0}$ is the mean of responses of all the experiment, $b_{j}$ coefficient represents the effect of the variable $X_{i}$ and $b_{i j}$, are the coefficients of regression which represent the effects of interactions of variables $\mathrm{X}_{\mathrm{i}} \mathrm{X}_{\mathrm{j}}$ and $\mathrm{b}_{\mathrm{ii}}$, are coefficients of regression which represent the effects of interactions $X_{\mathrm{i}} X_{j}$ and $\varepsilon$ is the experimental error, such that

$\mathrm{Y}_{1}=\mathrm{b}_{0}+\mathrm{b}_{1} \mathrm{~A}+\mathrm{b}_{2} \mathrm{~B}+\mathrm{b}_{3} \mathrm{C}+\mathrm{b}_{4} \mathrm{~A}^{2}+\mathrm{b}_{5} \mathrm{~B}^{2}+\mathrm{b}_{6} \mathrm{C}^{2}+\mathrm{b}_{7} \mathrm{AB}$

$+\mathrm{b}_{8} \mathrm{BC}+\mathrm{b}_{9} \mathrm{CA}+\mathcal{E}$

(Eq.3)

Where $Y_{1}$ is the response $1, b 1-b 9$ is the regression coefficient, $\mathrm{A}$ is the strontium substitution, $\mathrm{B}$ is the ignition temperature and $\mathrm{C}$ is the synthesis time. This model was used to evaluate the same responses $\left(\mathrm{Y}_{1}, \mathrm{Y}_{2}\right)$, such as $\mathrm{Y}_{1}$ the yield $(\%)$ and $\mathrm{Y}_{2}$ the crystallite size $(\mathrm{nm})$. The design matrix of experiments, in real values obtained according to the optimized Box-Behnken design, as shown in Table 1. The three key controllable process parameters (Strontium substitution, ignition temperature and synthesis time) were selected; these factors were investigated at three levels: strontium substitution $(0 \%, 15 \%$, and $30 \%)$, ignition temperature $\left(400{ }^{\circ} \mathrm{C}, 500{ }^{\circ} \mathrm{C}\right.$, and $\left.600{ }^{\circ} \mathrm{C}\right)$, synthesis time $(20$ $\mathrm{min}, 30 \mathrm{~min}, 40 \mathrm{~min})$. Each factor level represented minimum $(-1)$, centrepoint $(0)$, and maximum values $(+1)$, respectively. Therefore 17 experimental runs were conducted in BoxBehnken design.

\section{RESULTS AND DISCUSSION}

The factors and the responses from the results of the synthesized powders with Box-Behnken experimental design are presented in Table 1. Analysis of the regression coefficients of the quadratic polynomial models describing the relationship between the responses of yield and crystallite Size against the three factors (A, B, C) are presented in the following sections.

Table 1. Box-Behnken design trial experiments

\begin{tabular}{|c|c|c|c|c|c|}
\hline \multirow{3}{*}{ Exp. No } & Factor 1 & Factor 2 & Factor 3 & $\begin{array}{l}\text { Respo } \\
\text { nse } 1\end{array}$ & $\begin{array}{l}\text { Respons } \\
\text { e } 2\end{array}$ \\
\hline & $\begin{array}{l}\mathrm{A}: \mathrm{Sr} \\
\text { Substitut }\end{array}$ & $\begin{array}{l}\text { B:Temp } \\
\text { erature }\end{array}$ & C:Time & Yield & $\begin{array}{l}\text { Crystalli } \\
\text { te Size }\end{array}$ \\
\hline & $\%$ & ${ }^{\circ} \mathrm{C}$ & $\min$ & $\%$ & $\mathrm{~nm}$ \\
\hline N1 & 0 & 400 & 30 & 26 & 14 \\
\hline $\mathrm{N} 2$ & 30 & 400 & 30 & 23 & 38 \\
\hline N3 & 0 & 600 & 30 & 33 & 22 \\
\hline N4 & 30 & 600 & 30 & 28 & 49 \\
\hline N5 & 0 & 500 & 20 & 30 & 10 \\
\hline N6 & 30 & 500 & 20 & 25 & 40 \\
\hline N7 & 0 & 500 & 40 & 29 & 23 \\
\hline N8 & 30 & 500 & 40 & 26 & 50 \\
\hline N9 & 15 & 400 & 20 & 22 & 16 \\
\hline N10 & 15 & 600 & 20 & 29 & 23 \\
\hline N11 & 15 & 400 & 40 & 25 & 45 \\
\hline N12 & 15 & 600 & 40 & 21 & 57 \\
\hline N13 & 15 & 500 & 30 & 36 & 33 \\
\hline N14 & 15 & 500 & 30 & 36 & 33 \\
\hline N15 & 15 & 500 & 30 & 36 & 33 \\
\hline N16 & 15 & 500 & 30 & 36 & 33 \\
\hline N17 & 15 & 500 & 30 & 36 & 33 \\
\hline
\end{tabular}

\subsection{Yield Model Development}

The 2D surface and 3D contour plots illustrated in Figure 1 and 2 examine the effects of the two significant factors (ignition temperature and synthesis time) on the yield response. The results indicate that both the ignition temperature and the synthesis time exert a significant effect on the response for phase purity. It is clear that strontium substitution at $15 \%$ results in marked increase in the yield.

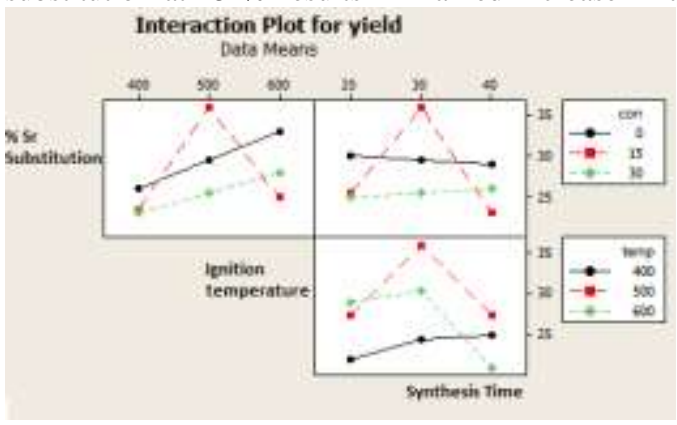

Figure. 1 Interaction between process parameters for yield 


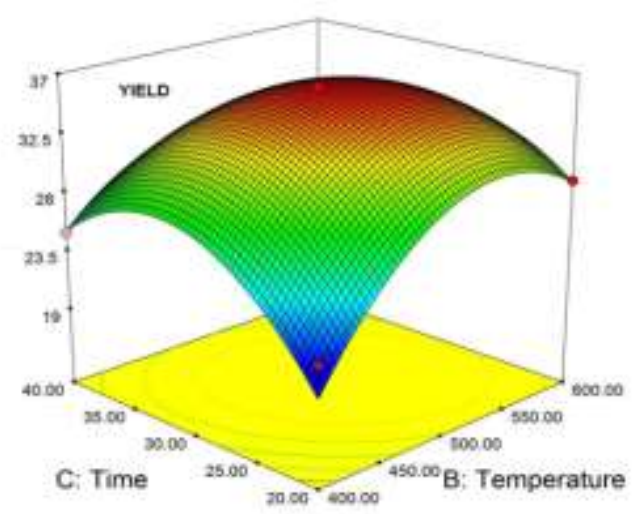

Figure. 2 3D graphs on interaction for yield

The maximum yield of 36.1541 occurs at a ignition temperature of $500^{\circ} \mathrm{C}$ and synthesis time of $30 \mathrm{~min}$. at a strontium substitution of $15 \%$. As a result of analyzing the measured responses using the Design Expert software, the test for significance of the regression models and the test for significance on individual model co-efficient were performed using the same statistical software package for all responses. By selecting the stepwise regression method, the insignificant model terms $(\mathrm{P}<0.05)$, were automatically eliminated. The resulting ANOVA table (Table 2) for the reduced linear phase purity model outlines the analysis of variance for this response and show the significant model terms affecting the yield.

Table 2 ANOVA Results for quadratic model

\begin{tabular}{llccccc}
\hline Source & $\begin{array}{l}\text { Sum } \\
\text { of } \\
\text { squares }\end{array}$ & df & $\begin{array}{c}\text { Mean } \\
\text { squares }\end{array}$ & F-value & R-value \\
\hline Model & 442.68 & 6 & 73.78 & 40.15 & $<0.0001$ \\
A-Sr substitution & 32.00 & 1 & 32.00 & 17.41 & 0.0019 \\
B-Temperature & 28.13 & 1 & 28.13 & 15.31 & 0.0029 \\
$\mathrm{~B}^{*} \mathrm{C}$ & 30.25 & 1 & 30.25 & 16.46 & 0.0023 \\
$\mathrm{~A}^{2}$ & 29.01 & 1 & 29.01 & 15.79 & 0.0026 \\
$\mathrm{~B}^{2}$ & 145.33 & 1 & 145.33 & 79.09 & $<0.0001$ \\
$\mathrm{C}^{2}$ & 145.33 & 1 & 145.33 & 79.09 & $<0.0001$ \\
Residual & 18.38 & 10 & 1.84 & & \\
Lack of fit & 18.38 & 6 & 3.06 & & \\
Pure error & 0 & 4 & 0 & & \\
Cor Total & 461.06 & 16 & & & \\
\hline
\end{tabular}

$\mathrm{R}^{2}=0.9601$, Adj. $\mathrm{R}^{2}=0.9362$, Pred. $\mathrm{R}^{2}=0.7674$, Adeq.

Precision $=18.825$

This table also shows other adequacy measures, such as, $\mathrm{R}^{2}$, Adjusted $\mathrm{R}^{2}$ and Predicted $\mathrm{R}^{2}$. All the adequacy measures should converge close to 1 , which is in reasonable agreement in indicating adequate models. The adequate precision in this case is 18.825 . An adequate precision ratio of greater than 4 indicates adequate model discrimination. The analysis of variance, indicates, that for the yield model, two of the combustion synthesis parameters have an effect on the resulting yield model, either as a main or interaction effect with another parameter. The main effects of the strontium substitution(A), ignition temperature (B) and the quadratic effects of ignition temperature*synthesis time $(B * C)$, strontium substitution $\left(\mathrm{A}^{2}\right)$, ignition temperature $\left(\mathrm{B}^{2}\right)$ and synthesis time $\left(\mathrm{C}^{2}\right)$ are the most significant model terms associated with yield. The final mathematical models in terms of coded factors, as determined by the design expert software are shown in Equation 4.

$$
\begin{aligned}
\text { Yield }= & 36-2 * \mathrm{~A}+1.88 * \mathrm{~B}-2.75 *(\mathrm{~B} * \mathrm{C})-2.65 * \mathrm{~A}^{2} \\
& -5.88 * \mathrm{~B}^{2}-5.87 * \mathrm{C}^{2}
\end{aligned}
$$

\subsection{Crystallite size model development}

Figure 3 and 4 shows the 2D and 3D contour graphs, highlighting the significant interaction effect between the strontium substitution and ignition temperature at synthesis times of between 20 to $40 \mathrm{~min}$.

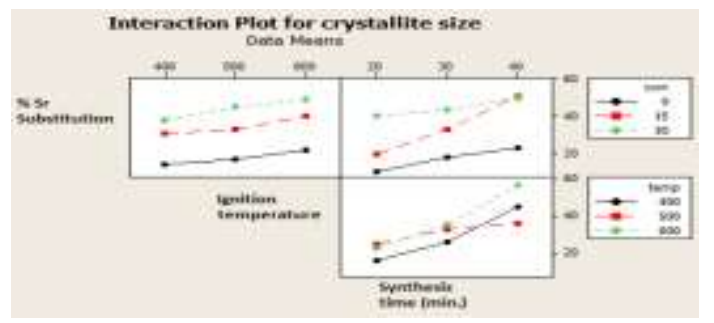

Figure. 3 Interaction between process parameters for crystallite size It is clear from this figure that an increase in the synthesis time produces a marked increase in crystallite size, while a reduction in the synthesis time appears to favour this response. A low value (20 $\mathrm{min})$ of synthesis time also appears

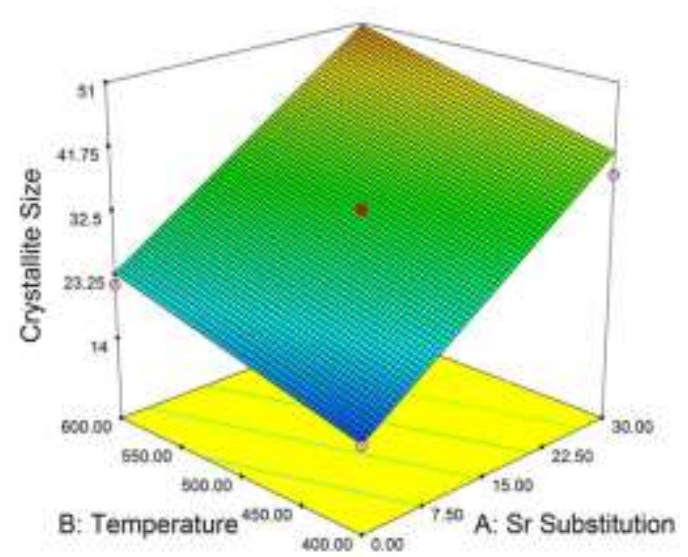

Figure. 4 3D surface graphs for interaction between process parameters 
to favour an decrease in crystallite size. As a result of analyzing the measured responses using the same statistical software used for this study, the fit summary output indicated that for the response concerning crystallite size, the quadratic model is statistically recommended for further analysis as this has the maximum predicted and adjusted $\mathrm{R}^{2}$. The test for significance of the regression model, the test for significance on individual model coefficients and the lack of fit test were performed for this response. By selecting the step-wise regression method, the insignificant model terms were automatically eliminated. The resulting ANOVA table (Table 3 ) for the reduced quadratic models outline the analysis of variance of each response and show the significant model terms.

Table 3 ANOVA Results for quadratic model

\begin{tabular}{lcccccc}
\hline Source & $\begin{array}{l}\text { Sum } \\
\text { of } \\
\text { squares }\end{array}$ & df & $\begin{array}{c}\text { Mean } \\
\text { squares }\end{array}$ & F-value & R-value \\
\hline Model & 2563 & 3 & 854.33 & 40.05 & $<0.0001$ \\
A-Sr substitution & 1458 & 1 & 1458 & 69.88 & $<0.0001$ \\
B-Temperature & 180.5 & 1 & 180.5 & 8.65 & 0.0115 \\
C-Time & 924.5 & 1 & 924.5 & 44.31 & $<0.0001$ \\
Residual & 271.24 & 13 & 20.86 & & \\
Lack of fit & 271.24 & 9 & 30.14 & & \\
Pure error & 0 & 4 & 0 & & \\
Cor Total & 2834.24 & 16 & & & \\
\hline
\end{tabular}

$\mathrm{R}^{2}=0.9043$, Adj. $\mathrm{R}^{2}=0.8822$, Pred. $\mathrm{R}^{2}=0.8002$, Adeq. Precision $=21.889$

The same table show also the other adequacy measures $R^{2}$, Adjusted $\mathrm{R}^{2}$ and Predicted $\mathrm{R}^{2}$, with an Adequate Precision Ratio of 21.889 , to indicate adequate model discrimination was achieved and shows that elimination quadratic terms did not have an influence on attaining a significant model. The order of significance for these effects follows the order: $\mathrm{C}$ $>A>B$. Final model in terms of coded factors is shown in Equation (5).

Crystallite size $=32.47+13.5 * \mathrm{~A}+4.75 * \mathrm{~B}+10.75 * \mathrm{C}($ Eq.5)

The three process parameters have a slightly positive effect on the crystalline size. It is evident that positive linear relationship of these three process parameters increases the crystallite size. Increase in the value of the process parameters increases the crystallite size.

\subsection{Optimization}

The above equation 5 indicates that the order of the level of significance of the positive effects of the combustion synthesis process parameters on the crystalline size follows the order: $(\mathrm{C})>(\mathrm{A})>(\mathrm{B})$, while there is no negative effects of the combustion synthesis process parameters.

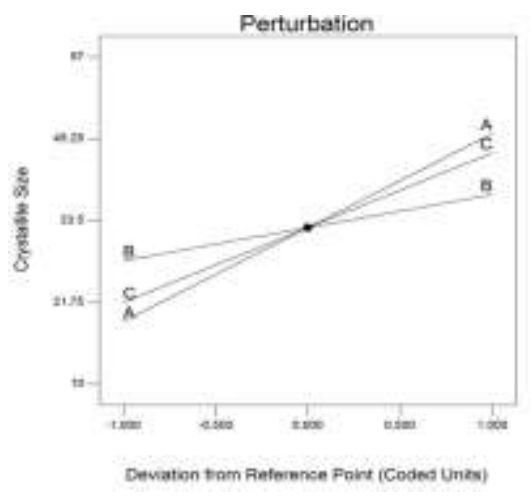

Figure. 5 Effect of the process parameters on the crystallite size

The perturbation plot aids in comparing the effect of all the factors at a particular point in the design space. Figure 3 shows a comparison between the effects of strontium substitution, ignition temperature and synthesis time on the minimum crystalline size.

\section{CONCLUSIONS}

The three level factorial Box-Behnken design was applied to study the two responses in synthesis of Sr-HAp by solution combustion method. Strontium substitution and ignition temperature were significantly affect final yield for experimental conditions. Strontium substitution, ignition temperature and synthesis time were significantly affect final crystallite size for experimental conditions. Sr-HAp possessing optimum powder characteristics can be prepared using the following solution combustion process parameters: Strontium substitution can be carried out at the ignition temperature of about $500^{\circ} \mathrm{C}$ for a synthesis time of $30 \mathrm{~min}$. to get maximum yield having a nano range crystallite size.

\section{ACKNOWLEDGMENTS}

The authors thank Dr.R.Narayanan and Dr.V.Somasundara Vinoth for their support in completing this work.

\section{REFERENCES}

[1] Predoi, D. Vatasescu-Balcana, R.A. Pasuk, I. Trusca, R. Costache, M. 2008. Calcium phosphate ceramics for biomedical applications, Journal of optoelectronics and advanced materials vol. 10, no. 8, (August 2008), 2151 -2155 .

[2] Orlovskii, V. P. Komlev, V. S. and Barinov, S. M. 2002. Hydroxyapatite and Hydroxyapatite-Based Ceramics Inorganic Materials, Vol. 38, No. 10, (2002). 973-984.

[3] Nezahat Kivrak and Cuneyt Tas, A. 1998. Synthesis of Calcium Hydroxyapatite-Tricalcium Phosphate Composite Bioceramic Powders and Their Sintering Behavior, J. Am. Ceram. Soc., (1998) 81 [9] 2245-52.

[4] Lin Yingguang, Yang Zhuoru, Cheng Jiang, Wang Lianshi. 2008. Synthesis, Characterization and Antibacterial Property of Strontium Half and Totally 
Substituted Hydroxyapatite Nanoparticles Journal of Wuhan University of Technology-Mater. Sci. Ed. (Aug 2008) 475-479.

[5] Valentina Aina, Gigliola Lusvardi, Basil Annaz, Iain R. Gibson, Flora E. Imrie, Gianluca Malavasi, Ledi Menabue, Giuseppina Cerrato and Gianmario Martra. 2012. Magnesium- and Strontium-co-substituted hydroxyapatite: the effects of doped-ions on the structure and chemico-physical properties. J Mater Sci: Mater Med (2012) 23. 2867-2879.

[6] Mardziah, C.M. Sopyan, I. and Ramesh, S. 2009. Stronti um-Doped Hydroxyapatite Nanopowder via Sol-Gel Method: Effect of Strontium Concentration and Calcination Temperature on Phase Behavior, Trends Biomater. Artif. Organ. (2009) Vol. 23(2), 105-113.
[7] Gross, A. Jersova, A. Grossin, D. Rey, C. Vīksna, A 2012. Formation of nanosized strontium substituted hydroxyapatites, Materials Science and Engineering. 38 (2012) 012032.

[8] Kehoe, S. and Stokes, J. 2011. Box-Behnken Design of Experiments Investigation Hydroxyapatite Synthesis for Orthopedic Applications ASM International, Volume 20(2), (2011) 306-316.

[9] Kwak J.S. 2005. Application of Taguchi and response surface methodologies for geometric error in surface grinding process, Int J Machine Tools Manuf, (2005), $45,327-34$.

[10] Gunaraj, V. Murugan, N. 1999. Application of response surface methodologies for predicting weld base quality in submerged arc welding of pipes. J Mater Process Technol, (1999), 88, 266-75. 